\title{
Necessity of Mentoring in Entrepreneurship Education: Reflection by Practitioners
}

\author{
Simeon Babatunde \\ Hatem El-Gohary
}

\section{Introduction:}

The significance of entrepreneurship education and its potential benefit to the wider community has led higher education institutions and providers in the UK and other countries to facilitate its pedagogy and andragogy in many various forms. It is mostly taught as an elective module, embedded into various course curriculums, or offered as a stand-alone degree program. The ultimate aim of these modules usually is to engender in students entrepreneurial competencies (Fayolle, 2013; Gartner, 1990; Matlay, 2009; Khalefa et al., 2013; Middleton, 2013).

Meanwhile, the delivery of entrepreneurship by various HEls takes various forms such as classroom focus, hands-on approach to set-up business, writing business plans, case studies, role play, provision of incubators, competitions, conferences, simulations, etc. (Henry et al., 2005). However, an important facet of the delivery and success of entrepreneurship education is mentoring, especially for those intending to explore their ideas. In this regard, mentoring boosts the likelihood of success been achieved by any budding entrepreneur, and it complements other forms of delivery (Peterman and Kennedy, 2003).

Furthermore, entrepreneurship education in HEls provides an avenue for students to interact with others and bring all their past and present learning to bear on entrepreneurship themed topic(s). As such, mentoring is a significant aspect of entrepreneurship education, predominantly in the formation and running of a business. 
The experience of mentoring is mostly gained from an experienced staff member or visiting entrepreneurs to guide a student through this process. The mentoring process provides equal benefits to the mentor as well as the mentee, and as a secondary benefit provides the opportunity for reverse mentoring through the mentee. Critical reflective practice is a key part of mentors' personal and professional development, and it enables them to improve and be accountable as academics or practitioners to enhance the mentoring process better.

This paper illustrates the need to further encourage reflection as part of mentoring, and leverage on the immense knowledge that could be gained from reverse mentoring during the process. As it is evidenced that mentoring has engendered success in various phases of entrepreneurship (Bridgstock, 2013; Rideout and Gray, 2013), this paper will highlight the benefits of mentoring in entrepreneurship education, for both the mentee and the mentor via reflection and reverse mentoring as supported by some scholars in the field such as Marcinkus (2012). The personal narrative here explores and reflect on the experience of practitioners and identifies areas to be explored in the future; this will influence practice and enhancing students experience. The paper provides engineering students and educators with a great opportunity to understand entrepreneurship mentoring which might help in creating a new generation of engineering entrepreneurs.

\section{Mentoring in Entrepreneurship Education:}

Mentoring has been variously defined, but a converging theme among all these definitions is that mentoring happens between two parties (a mentor and a mentee) in which, one party (the mentor) provides support, advice and encouragement to the mentee to enable the achievement of a set of objectives. The mentor is the more experienced, 
and by providing this to the less experienced (the mentee) he/she will help the mentee to fully engage in the entrepreneurship education process (St-Jean and Audet, 2012; Sullivan, 2000). However, it must be noted that goings-on in the mentoring relationship is largely driven by the mentee (Pegg, 1999). Mentoring is also viewed as "a developmental relationship that is embedded within the career context" (Ragins and Kram, 2007, p.5).

According to Burns (1995, p.99) "learning as a relatively permanent change in behaviour with behaviour including both observable activity and internal processes such as thinking, attitudes and emotions". Underlying mentoring is a learning process, and specifically, in this paper, the Kolb learning theory (experiential learning theory) fits in expanding such a learning process. The theory explains that learning takes place in a loop of four ways; these are through concrete experience, through observation and reflection, through abstract conceptualisation and finally active experimentation (Burns, 1995). The same concept of considering mentoring as a learning process also fits in with the social learning theory with posits observation, imitation and modelling. However, it is believed that mentoring is more of taping into the knowledge and experience bank of the mentor and having the confidence of someone to bounce ideas off (Bandura and Walters, 1977). These are normally evident during the mentoring process and hence lead to experiential learning for both the mentor and mentee (McGill and Beaty, 1995, pp. 1122).

Meanwhile, reverse mentoring is a key component as it enables the mentor to also, benefit from the interaction with the mentee whose life experience will provide an avenue to learn something new. The advantage of having an open mind to learn from a younger or less experienced person, especially regarding technology, social media, cultural 
changes, and new fads, becomes very important (Chaudhuri and Ghosh, 2012). Several studies outlined the benefits of both mentoring and reversed mentoring on behavioural, motivational, attitude, business and career choices of participants. These benefits are also an outcome of planning, structure and time commitment of both the mentor and the mentee (Allen et al., 2004; Eby et al., 2008).

The importance of subject knowledge to the mentor is enormously important; in entrepreneurship, mentors are predominantly those who have started their businesses, worked in businesses, occupied various positions, and those whose experiences can add value to budding entrepreneurs. Moreover, passion and dedication of the mentor are very important to the entire process, which requires time commitments, patience, value adding and provision of guidance all along the journey (Jack, and Anderson, 1999; and Van Auken et al., 2006). The importance of mentoring as an important part of an array of support in entrepreneurship complements andragogy and encourages Heutagogy (the study of self-determined learning), enabling the transition of ideas beyond papers and dreams to solid reality. Mentoring contributed immensely to entrepreneurship; it increases the ability of the mentee to see beyond their 'world' and 'outside the box'; with confidentiality is maintained all through the process (Cope and Watts, 2000; St-Jean and Audet, 2012).

\section{Entrepreneurship Education and Engineering Students:}

Although a notable number of scholars within the field examined entrepreneurship education for engineering students, only few of them examined the impact of entrepreneurship education on engineering students (e.g. Zhang et al. 2014; Tessema Gerba, 2012; Lo, 2011; Souitaris, et al. 2007; Menzies and Paradi, 2003; etc.). In this 
regard, Souitaris et al. (2007) illustrated that entrepreneurship education programmes affect entrepreneurial attitudes and intentions of science and engineering students to start a business. According to them, offering engineering students' entrepreneurship education programmes raise their overall entrepreneurial inspiration as well as entrepreneurial intentions. Lo (2011) confirmed the same relationship between entrepreneurship education and engineering students' entrepreneurial intentions (based on his study of 411 engineering students). Moreover, Nichols and Armstrong (2003) argue that engineering entrepreneurship is vital for improving engineering students' ability to deal with engineering and societal problems.

Within the same line, Tessema Gerba (2012) examined the impact of entrepreneurship education on 156 undergraduate engineering students' entrepreneurial intentions in Ethiopia. The finding of Tessema Gerba (2012) reinforced the findings of other scholars within the field and confirmed that engineering students' who completed entrepreneurship education courses to have better entrepreneurial intention than those who had not complete such courses in Ethiopia. Zhang et al. (2014) confirmed the same and illustrated based on their examination of 494 students from ten different universities that entrepreneurship education had a significant positive impact on entrepreneurial intentions. They also confirmed based on their findings that such impact was higher for males and people from technological universities and backgrounds. This match the findings of Menzies and Paradi (2003) who found that engineering male students who completed entrepreneurship courses at a major Canadian university proved to become business owners after graduating. 
Furthermore, form an engineering student point of view, entrepreneurship education is perceived to be a vital element in building a successful career. This was confirmed by the finding of Täks, et al. (2014) who found based on an in-depth qualitative examination that engineering students view entrepreneurship education in a variety of ways. Based on the findings Täks, et al. (2014), engineering students considered entrepreneurship education as a "first step to self-directed learning, a preparation for work life, a path to possible self-employment, and a context for developing leadership and repossibility for group achievement" (Täks, et al., 2014, P: 573).

\section{Reflection During the Mentoring Process:}

This paper utilises a reflection of the writers' experiences to outline the different benefits gained during the mentoring process to all stakeholders. Emphasis will be placed on skills developed and honed; and their importance in mentoring.

Reflection entails going back to an experience or an action, looking into what happened, what might have been done differently and ensuring that changes or improvements are implemented in subsequent events if necessary. Reflection entails thinking and adopting learning as a continuum (Boud et al., 1985). It is also essential to keep a record of reflections via a reflective journal which allows for a critical look during the review of journal entries; it allows for ownership while deepening learning and ultimately enhances personal and professional practice (Moon, 2013, pp.71-102). The process of reflecting during mentoring enhances the pursuit to become a better mentor and enhance the mentor ability to become a 'reflective practitioner' (Schön, 1983, pp.128166; 1987, pp.100-118). Larrivee (2000) also emphasised the significance of a mentor developing the practice of critical reflection to aid in becoming a better professional truly. 
It is a dynamic and continuous process, which requires a willingness to carry out selfcritical evaluations.

The mentoring experience reflected on provides a two-way approach, though a primary focus on mentoring students on entrepreneurship or entrepreneurship related modules (e.g. marketing, management, etc.), with the secondary benefit of reverse mentoring. The review of the authors experience is carried out below using Driscoll model of reflection which allows the mentor to ask 'what, so what and now what' questions (Driscoll, 1994). A mentoring life cycle was an important facet of this because the mentoring was for a period of time and the start and end date was set at the beginning. This was very much in line with the stages proposed by Hay (1995) which are Start phase, Establishing phase, developing independence phase, and termination phase. These phases were adopted and shown in the reflection.

\section{Applying Driscoll Model of Reflection to a Mentoring situation:}

\section{Brief background on the mentoring situation:}

As part of the entrepreneurship modules provided by a UK based university and the nature of some postgraduate programmes ( $\mathrm{PhD}$, DBA, etc.), some students approached the authors on more than one occasion to act as mentors for them, and the authors accepted having discussed expectations from a mentor and a mentee to all the students involved. Some of these students were engineering students completing their MBAs at a UK based university in addition to one Dutch engineering PhD student who was co-supervised by one of the authors. Based on the authors' experience of starting and managing a business, understanding the processes related to it and have the knowledge bank of the business phase; the students were at different stages of building 
a business, and a sufficient number of them were in the survival phase. Considering this, the authors accepted to act as mentors for the students in these different phases and gave extra mentoring attention to those students in the survival phase. The application of Kolb learning theory was key to the success of implementation after discussions with the students. During the authors' initial discussions with the students and as a secondary benefit, the authors explained to the mentees the benefit of reverse mentoring and its potential benefits to the authors as academics. The students (mentees) were in the final year of study at the undergraduate stage or MBA/MSc students and were keen on moving the proposed business idea(s) to the next phase. This mentoring experience brought to fore key skills required, and those developed on which the crux of the authors' reflection below will be based. The proposed timeframe for the relationship with deadlines was established at the very start of the mentoring processes.

\section{What? (Using Driscoll model):}

The purpose of returning to this situation is to enable the authors to reflect on the mentoring skills required, developed and honed throughout the entire process of been mentors to students, and the experience of taping into reverse mentoring. The following part of the paper highlight briefly some of these issues, and how the authors benefited from them within the process:

○ Active listening: This was very important throughout the process, it enabled the authors to understand the thoughts of the mentees fully, watch their body language, and provide them with guidance appropriately. The authors kept notes as mentees spoke and reconfirmed these during their discussions with them. The process enabled 
the authors to read beyond spoken words and value the importance of body language of their mentees.

Meanwhile, during the discussions, the mentees also kept notes to ensure that action points were noted for implementation. As the process continued, when the reverse mentoring started, the authors also kept notes to tap into the experiences of the students during the implementation of business ideas.

- Paraphrasing: To assure the mentees of the authors' full attention, the authors ensured a good grasp of what was said and discussed in their own words. This enabled the authors to identify areas where further probing was required and areas where gaps needed to be filled. This provided clarity and ensured no issues that required guidance were left unattended.

- Questioning: This process entailed asking questions to move things forward; these questions were generated from discussions had, and problems were identified. Questioning aimed to find probable solutions. A lot of room was provided for questioning from both the authors and the mentees, hence ensuring the meetings were very productive and intellectually challenging and resulted orientated. The authors asked a lot of questions during the process of reverse mentoring to ensure they were filling in their knowledge gap as it relates to technology (for one of the authors) and ongoing cultural changes.

- Action planning: As a follow up to the discussions between the authors and their mentees, a summary of what needs to be done were agreed with relevant timescales. Both the authors and mentees ensured that targets sets were specific, measurable, achievable, realistic and timely. This was very much in line with ensuring that both 
parties kept to the 'Mentoring Life Cycle' they had set at the very start of the mentoring process. Moreover, the authors requested and got progress report during the implementation of ideas, hence ensuring any questions were noted for future meetings with mentees.

- Reflective diary: the authors kept a reflective journal to help with recording their thoughts after each meeting with each mentee. The authors also encouraged each student (mentee) to do the same. This goes in line with Kolb learning theory. The authors' reflective diary enabled them to identify what went well during the mentoring process, what could have been done in a better way and what could be done in the future to ensure good mentoring.

Meanwhile, the other advantage of the reflective diary was the opportunity to get lessons that would influence the authors practice as both academics and practitioners. Lessons learnt during the process of reverse mentoring influenced future examples in the classroom and would influence future mentoring experience, hence enhancing the authors practice.

- Feedback: the authors provided feedback to their mentees after the implementation of any action plan, and this was very useful in moving the process forward. The authors also requested feedback from the mentee at intervals and the end of the mentoring process. The use of technology during the process saved time and aided communications during the mentoring process. It is evidenced by research that $\mathrm{e}-$ mentoring promotes communication with the use of tools such as: Skype, email and phone calls (Ullmann et al., 2011; Hunt, 2005; Bierema and Merriam, 2002), though 
evidence suggests care must be taken to avoid an over-dependence on these tools, and ensure that face-to-face communication continues (Smith-Jentsch et al., 2008).

\section{So what? (Using Driscoll model):}

The authors initial impression at the start of the mentoring process was that of apprehension due to the whole array of skills required and the complexity that could arise; though the authors were confident of their skills set and had the needed experience to guide the student. The authors were keen on the student learning and engagement during the process, and ultimately achieving the aim set at the start of the mentoring journey which was moving the business to the next phase.

At the end of the process, the entire experience provided the authors with invaluable skills, new information and idea gleaned from reverse mentoring. All these have been of value in subsequent mentoring and teaching in the classroom. Specifically, the authors developed the art of active listening (Mullen and Noe, 1999), as it forms the bedrock of the entire mentoring process.

\section{Now what? (Using Driscoll model):}

The entire mentoring experiences provided the authors with the opportunity to recognise the value and significance of active listening and to get to comprehend the peculiarity of each mentee in addition to how to develop a successful working relationship. The authors further appreciated the importance of asking useful questions during discussions with the mentees (Eby et al., 2006).

The importance of keeping up to date knowledge with latest developments in the macro environment, and how it could have an impact on decisions was something that came to bear because businesses are impacted by these factors and need to react 
appropriately. The importance of getting students starting businesses to keep abreast of this is something to stress going forward. Also, the need to have certain information on where to source these from was also noted. To further enhance the authors practice and that of entrepreneurship education, the views of other practitioners and mentees were explored, and the benefits of reverse mentoring to academics should be promoted. As such, the need to enhance listening and continue critical reflection should form part of the continuous personal development of any academic mentor.

\section{Conclusion and Recommendation:}

The experience of acting as a mentor further buttressed its importance to the process of successful entrepreneurship education in HEls (Bisk, 2002; Eby et al., 2006; Sullivan, 2000; Ensher et al., 2000). Its benefits to the mentee and the authors were numerous; the ultimate benefit been the success of mentees in achieving the planned aim of the journey. The benefits to the authors as mentors were numerous, and most especially beneficial in reverse mentoring by the mentees. The outline of some of the potential benefits to the mentor is improved communication skills with younger generations of entrepreneurs, listening skills; reinforcement of knowledge, improved confidence (for one of the authors), improved awareness of culture and technology in the macro environment, and very importantly a sense of fulfilment.

The feedback obtained from the mentees highlighted the numerous and valuable benefits of mentoring to them; few of these are access to practical advice and support; improved confidence, improved communication and planning skills, learning from the experience of others, the importance of building a network of contacts and ability to make 
decisions. Moreover, the mentoring process enabled the mentees to move towards selflearning (St-Jean and Audet, 2012; Wilbanks, 2013).

This paper has highlighted the positive impacts of mentoring to the mentor, mentee and practice; it recommends the continued adoption of mentoring in entrepreneurship education and similar practices. It also highlights the need to explore further the benefit of reverse mentoring and developing a bespoke checklist for mentoring in entrepreneurship education (Marcinkus, 2012; Leh, 2005).

\section{References:}

Allen, T.D., Eby, L.T., Poteet, M.L., Lentz, E. and Lima, L. (2004), "Career benefits associated with mentoring for protégés: A meta-analysis", Journal of applied psychology, 89(1), p.127.

Alsharief, R. and El-Gohary, H. (2016). Entrepreneurship Education for Higher Education Students in KSA and its Impact on Their Employability: An Empirical Investigation, International Journal of Business and Social Science, 7(6), pp: 83-100.

Bandura, A. and Walters, R.H., 1977. Social learning theory (Vol. 1). Englewood Cliffs, NJ: Prentice-hall.

Bierema, L. and Merriam, S. (2002), "E-mentoring: Using computer-mediated communication to enhance the mentoring process", Innovative Higher Education, 26(3), pp. 211-227.

Bisk, L. (2002), "Formal entrepreneurial mentoring: the efficacy of third party managed programs", Career Development International, 7(5), pp. 262-270.

Boud, D., Keogh, R., and Walker, D. (1985), Reflection: Turning experience into learning. Routledge. 
Bridgstock, R. (2013), "Not a dirty word: Arts entrepreneurship and higher education", Arts and Humanities in Higher Education, 12(2-3), pp. 122-137.

Burns, R. (1995), The adult learner at work Business and Professional Publishing. Sydney Chaudhuri, S. and Ghosh, R. (2012), "Reverse mentoring: A social exchange tool for keeping the boomers engaged and millennials committed", Human resource development review, 11(1), pp.55-76.

Cook, J., and Oliver, M. (2002), "Designing a toolkit to support dialogue in learning", Computers \& Education, 38(1), pp. 151-164.

Cope, J. and Watts, G. (2000), "Learning by doing-an exploration of experience, critical incidents and reflection in entrepreneurial learning", International Journal of Entrepreneurial Behaviour \& Research, 6 (3), pp. 104-124.

Driscoll J. (1994), "Reflective practice for practise", Senior Nurse, 13(1), pp. 47 -50.

Eby, L.T., Allen, T.D., Evans, S.C., Ng, T. and DuBois, D.L. (2008), "Does mentoring matter? A multidisciplinary meta-analysis comparing mentored and non-mentored individuals", Journal of vocational behavior, 72(2), pp.254-267.

Eby, L., Durley, J., Evans, S., and Ragins, B. (2006), "The relationship between shortterm mentoring benefits and long-term mentor outcomes", Journal of Vocational Behavior, 69(3), pp. 424-444.

Eid, R., Badawi, A., Selim, H., and Elgohary, H. (2017). Entrepreneurship education and employability of UAE higher education business students, 10th annual International Conference of Education, Research and Innovation, 16-18 of November, 2017 - IATED, Seville, Spain, DOI: 10.21125/iceri.2017.1985. 
El-Gohary, H. Selim, H., and Eid, R. (2016). Entrepreneurship Education and Employability of Arab HE Business Students: An Attempt for a primary investigation, International Journal of Business and Social Science, 7(4), pp: 52-72.

El-Gohary, H, and Eid, R., (2013). Leadership Teaching Impact on Tourism Students' Attitudes and Perceptions towards Leadership in Developing Economies: The Case of Egypt, Journal of Hospitality \& Tourism Education, 25 (4), pp: 180-192.

El-Gohary, H, O'Leary, S. and Radway, P. (2012). Investigating the Impact of Entrepreneurship Online Teaching on Science and Technology Degrees on Students attitudes in Developing Economies: The case of Egypt, International Journal of Online Marketing (IJOM), 2 (1), pp: 29-45.

Ensher, E., Murphy, S. and Vance, C. (2000), "Mentoring and self-management career strategies for entrepreneurs", The international journal of entrepreneurship and innovation, 1(2), pp. 99-108.

Fayolle, A. (2013), "Personal views on the future of entrepreneurship education", Entrepreneurship \& Regional Development, 25(7-8), pp. 692-701.

Gartner, W. (1990), "What are we talking about when we talk about entrepreneurship?" Journal of Business venturing, 5(1), pp. 15-28.

Hay, J. (1995), Transformational mentoring: Creating developmental alliances for changing organizational cultures. McGraw-Hill.

Henry, C., Hill, F. and Leitch, C. (2005), "Entrepreneurship education and training: can entrepreneurship be taught? Part l", Education+ Training, 47 (2), pp. 98-111.

Hunt, K. (2005), "E-mentoring: solving the issue of mentoring across distances", Development and Learning in Organizations: An International Journal, 19 (5), pp. 7-10. 
Jack, S. L., \& Anderson, A. R. (1999), "Entrepreneurship education within the enterprise culture: producing reflective practitioners", International Journal of Entrepreneurial Behaviour \& Research, 5(3), pp. 110-125.

Khalefa, M., Zhang, Y., Forrester, P., and El-Gohary, H. (2013). Factors Affecting International Entrepreneurship (IE) Performance: A Review of Literature, proceedings of the ISBE 2013 Conference, Escape Velocity: Internationalising Small Business Environments, Cardiff, UK, 12th and 13th November 2013.

Larrivee, B. (2000), "Transforming teaching practice: Becoming the critically reflective teacher", Reflective Practice, 1(3), pp.293-307.

Leh, A.S. (2005), "Lessons learned from service learning and reverse mentoring in faculty development: A case study in technology training", Journal of Technology and Teacher Education, $13(1)$, pp. 25 - 41.

Lo, C. T. (2011). The impact of entrepreneurship education on entrepreneurial intention of engineering students (Doctoral dissertation, City University of Hong Kong).

Marcinkus, M. W. (2012), "Reverse mentoring at work: Fostering cross-generational learning and developing millennial leaders" Human Resource Management, 51 (4), pp.549-573.

Matlay, H. (2009), "Entrepreneurship education in the UK: a critical analysis of stakeholder involvement and expectations", Journal of Small Business and Enterprise Development, 16 (2), pp. 355-368.

McGill, I. and Beaty, L. (1995), Action Learning: a guide for professional, management and educational development, Kogan Page, London. 
Menzies, T. V., \& Paradi, J. C. (2003). Entrepreneurship education and engineering students: Career path and business performance. The International Journal of Entrepreneurship and Innovation, 4(2), 121-132.

Middleton, K. (2013), "Becoming entrepreneurial: gaining legitimacy in the nascent phase", International Journal of Entrepreneurial Behaviour \& Research, 19 (4), pp. 404424.

Moon, J. A. (2013), A handbook of reflective and experiential learning: Theory and practice. Routledge.

Mullen, E. and Noe, R. (1999), "The mentoring information exchange: when do mentors seek information from their protégés?", Journal of Organizational Behavior, 20(2), pp.233-242.

Nichols, S. P., \& Armstrong, N. E. (2003). Engineering entrepreneurship: does entrepreneurship have a role in engineering education?. IEEE Antennas and Propagation Magazine, 45(1), 134-138.

Pegg, M. (1999), "The art of mentoring”, Industrial and Commercial Training, 31 (4), pp. 136-142.

Peterman, N. and Kennedy, J. (2003), "Enterprise education: Influencing students' perceptions of entrepreneurship", Entrepreneurship theory and practice, 28 (2), pp. 129144.

Ragins, B. and Kram, K. (2007), "The roots and meaning of mentoring", The handbook of mentoring at work: Theory, research, and practice, pp. 3-15.

Rideout, E. and Gray, D. (2013), "Does Entrepreneurship Education Really Work? A Review and Methodological Critique of the Empirical Literature on the Effects of 
University-Based Entrepreneurship Education", Journal of Small Business Management, 51 (3), pp. 329-351.

Schön, D. A. (1983), The reflective practitioner: How professionals think in action. Basic books, New York.

Schön, D. A. (1987), Educating the reflective practitioner. San Francisco: Jossey-Bass.

Smith-Jentsch, K., Scielzo, A., Yarbrough, C., and Rosopa, P. (2008), "A comparison of face-to-face and electronic peer-mentoring: Interactions with mentor gender", Journal of Vocational Behavior, 72 (2), pp.193-206.

Souitaris, V., Zerbinati, S., \& Al-Laham, A. (2007). Do entrepreneurship programmes raise entrepreneurial intention of science and engineering students? The effect of learning, inspiration and resources. Journal of Business Venturing, 22(4), 566-591.

St-Jean, E., and Audet, J. (2012), "The role of mentoring in the learning development of the novice entrepreneur". International Entrepreneurship and Management Journal, 8(1), pp. 119-140.

Sullivan, R. (2000), "Entrepreneurial learning and mentoring", International Journal of Entrepreneurial Behaviour \& Research, 6(3), pp. 160-175.

Täks, M., Tynjälä, P., Toding, M., Kukemelk, H., \& Venesaar, U. (2014). Engineering students' experiences in studying entrepreneurship. Journal of engineering education, 103(4), 573-598.

Tessema Gerba, D. (2012). Impact of entrepreneurship education on entrepreneurial intentions of business and engineering students in Ethiopia. African Journal of Economic and Management Studies, 3(2), 258-277. 
Ullmann, T. D., Ferguson, R., Buckingham Shum, S., and Deakin Crick, R. (2011), Designing an online mentoring system for self-awareness and reflection on lifelong learning skills. Available online from: http://oro.open.ac.uk/30603/1/arple$2011 \% 28006904 v 1 \% 29 . p d f$ [accessed on 10 February, 2014 2013]

Van Auken, H., Fry, F. and Stephens, P. (2006), "The influence of role models on entrepreneurial intentions", Journal of Developmental Entrepreneurship, 11(2), pp. 157167.

Wilbanks, J.E. (2013), "Mentoring and entrepreneurship: Examining the potential for entrepreneurship education and for aspiring new entrepreneurs", Journal of Small Business Strategy, 23(1), pp. $93-101$.

Zhang, Y., Duysters, G., \& Cloodt, M. (2014). The role of entrepreneurship education as a predictor of university students' entrepreneurial intention. International entrepreneurship and management journal, 10(3), 623-641. 